\title{
UNIVERSITY BOTANICAL TEACHING AND TRAINING
}

$\mathrm{I}^{\mathrm{N}}$ Nature of April 28, 1951, the leading article raised the importance of university departments of biology (both botany and zoology) for the training of biologists to satisfy the needs of the modern State. We then pointed out that among those working in the wide and varied field of applied biology there was a general conviction that Great Britain and the Commonwealth was suffering from a dearth of plant and animal physiologists. This article inspired Sir William Slater to write shortly afterwards (Nature of June 2, 1951) to point out that the Agricultural Research Council was seriously concerned about the shortage of animal and plant physiologists with an adequate knowledge of chemistry and physics and of biochemists with biological experience, and to emphasize the important efforts which the Council was making in this direction.

This adds point, therefore, to the discussion organized by Section K (Botany) of the British Association on September 5 at Belfast. The discussion is fully reported in the following columns by Prof. L. J. Audus. The three main contributors to the discussion--.Dr. Eric Ashby, Dr. W. B. Turrill and Mr. Peter Bell-raised issues of the utmost importance. We felt, however, that this was a very important discussion, and that it, like most discussions in connexion with which no special invitations to speak had been accorded to anyone other than the readers of the main papers, might prove to be an unbalanced review of authoritative opinion throughout the country, in spite of the fact that a number of botanists contributed useful points after the papers had been read.

So it was decided to approach a number of other botanists who either were not present at the discussion, or, if they were, did not speak, to contribute their views now. Copies of Prof. Audus's report were sent to them and their comments follow the main report here. In most cases, no department of botany was approached if one of its members had spoken at the Belfast meeting. It should be pointed out, however, that Prof. Audus himself was invited to submit a written comment, since, with the aim of making his written report as objective as possible, he did not speak at the discussion itself. A few authorities, for specific reasons, preferred not to contribute to this discussion.

Although in most cases the head of the department was originally approached, and in some cases it seems that he consulted his assistants, it should not be taken for granted that any one contribution is the considered opinion of the entire department concerned.

It will be noted, as one might expect, that the opinions expressed indicate that the problem is heterogeneous ; for example, the small department has problems which the large department does not have to face. Moreover, individual authorities raise special points. But apart from this, there are several general themes which have been brought out, and these might with advantage be given careful consideration by all university and college departments of botany.

\section{The British Association Discussion}

THE rapid expansion of botany as a university subject in recent years and its growing importance in a world faced with grave food shortages has recently caused university staffs to reconsider whether present degree courses are suited to modern needs. A whole morning's session in Section K (Botany) of the British Association was devoted to "The University Training of a Botanist" at the Belfast meeting on September 5.

DR. ERIC ASHBY (QUEEN'S UNIVERSITY, BELFAST), who opened the discussion, explained that the purpose of his paper was to examine the botanical curriculum, its determining factors and the case for its reform. To keep the discussion within bounds it was necessary to limit its scope to honours courses in botany considered solely as a training for professional botanists (not including school teachers).

The curriculum should be influenced by : (1) the corpus of botanical knowledge and fields of current research ; (2) the requirements of employers ; (3) the aptitudes of students. Other 'illegitimate' influences, for example, the bias of university staff and inertia of examiners, would be disregarded.

(1) The corpus of botanical knowledge has changed enormously since 1900. From 1900 until 1910 it was sufficient only to know botany in order to understand any botanical research paper. From 1940 until 1950 many papers could not be understood without some knowledge of chemistry, mathematics and physics. The change was illustrated by a study of examination papers over the past fifty years. Thus the examinee of 1950 was expected to answer some 95 per cent of questions set forty to fifty years ago, whereas an examinee of 1900-10 could not have attempted some 40 per cent of the 1950 questions. By and large, honours botany curricula still contain as much comparative morphology, etc., as they did in 1910, while genetics, much more physiology, ecology and cytology have all been squeezed in without any lengthening of the course.

At the research-level the classical problems are still relevant and no nearer solution than they were fifty years ago, and we would do a serious disservice to our subject if we discarded those problems or no longer taught the raw materials necessary for thinking about them. Meanwhile most botany research workers prefer fields where solutions are easier to obtain, as is shown by the type of research taken up by British postgraduate botany students in 1951 (University Grants Committee data), that is, taxonomy 8; genetics 30 ; ecology 16 ; physiology 22 ; pathology 16; mycology 14. Thus the content of botany has enormously enlarged, yet the material included fifty years ago cannot be entirely discarded. This is the dilemma of the botanical curriculum.

(2) Universities are primarily institutions for training professional men and women. In 1900 most botanists were employed by universities, herbaria and botanical gardens. To-day there is a much wider range of employers. Apart from the teaching profession, the biggest employer of botanists is the Government (Agricultural Research Council and 
Department of Scientific and Industrial Research), then the Colonial Service and then the universities. Demands are for physiologists, biochemists, pathologists, plant breeders and experimental ecologists. In 1950 the Ministry of Labour and National Service published a pamphlet stating that over the period 1950-54 the supply of honours botanists was likely to be about twice the demand. Although these demands were probably underestimated, yet even with adjustments the figures are disturbing. Notwithstanding this threatened excess, bodies like the Agricultural Research Council and the Colonial Office cannot get recruits of the right calibre or training for their vacancies [see also Nature, 167, 659 and 908; 1951]. The majority of honours botanists that apply can discuss at length the classical problems of morphology but cannot, for example, design the simplest field experiment in agricultural botany. They are therefore of no use to these principal employers.

(3) The aptitudes of botanical students have changed in the last fifty years: On the whole, in 1900, botanical students were naturalists. They had, therefore, good visual memories and enjoyed the techniques of evaluation as contrasted with measurement. But most modern botany students are fundamentally not naturalists. By temperament and aptitude they are experimentalists. For them field-work is difficult, and they must learn their plants anew each year. They are uninterested in the arguments of classical botanists. These two kinds of student are as different as chalk is from cheese yet we are forcing them both into the seme mould. The born taxonomist ploughs his way in misery through the tortuous paths of metabolism. The born physiologist suffers resignedly the unconvincing arguments of the morphologists. It is our duty to change the curriculum to meet the needs of both these types of botanist.

The conventional adjustment of the curriculum is usually to reduce the number of types, to skimp reading of classical papers, to cut practicals but never to leave even one group out. As a guide in making reforms, however, one should take as a model the techniques of the classics curriculum. There seem to be two principles involved. The first is to select a few authors and to study them exhaustively until one lives in the climate of their thought; the second is to ensure complete familiarity with comparatively few works of genius. The power of classical education depends on this second principle. This contrasts strongly with the principles underlying an honours course in botany. Here insistence on some contact with every aspect of the subject inevitably means that only the most superficial consideration can be given to any one subject and nothing can be studied exhaustively and really understood. On the experimental side this is particularly marked, and is positively harmful, for it misses the main point of experimental work, that it is not always successful and that the experimenter has to repeat and repeat until results are consistent. Furthermore, one can graduate well in botany without ever having opened a book by Darwin or read a paper by Sachs or F. F. Blackman, but not if one has omitted to struggle through a score of books by industrious but negligible writers just because they contain the most recent information.

Dr. Ashby next turned to some practical proposals. He first assumed that it is not possible on economic grounds to lengthen the honours botany course. This means that something must be omitted. The first omission should be compulsory zoology. Although it might be desirable for school teaching and certain very specialized jobs, the professional botanist has far more to learn from the chemist, the mathematician and the physicist. In the first post-intermediate year let all botanists do the same general course. The non-experimental botanist, who is easily distinguishable even at this stage, should take in addition geology and some zoology, while the experimental botanists should take instead chemistry and physics. In the second and third post-intermediate years they should be separated into two streams. The nonexperimentalists would take anatomy, comparative morphology and evolution, taxonomy, floristic plant geography, genetics; together with geology, some zoology and some climatology. The experimental botanist would take anatomy, physiology, experimental ecology, genetics, plant pathology, mycology ; together with chemistry, biochemistry, physics (properties of matter and some physical techniques), elementary mathematics and statistics. This would leave time for work to be done with a precision and thoroughness not devoted to it for forty years. It would, indeed, turn out botanists who had never 'done' the vascular cryptogams except in an elementary course and others who would not be able to read a modern paper on photosynthesis; but it would produce a taxonomist who has spent time on palæontology instead of wasting it on fat metabolism and a physiologist who knew enough physical chemistry to understand fully modern papers on salt absorption, etc.

DR. W. B. TURRILL (THE HERBARIUM, ROYAL BOTANIC GARDENS, KEW), who followed, confined his attention to the teaching of angiosperm systematics. He was tempted to suggest that taxonomy could not be taught. What can be done is to train the student to teach himself. However, the attempts that had been and still were being made to do so could be classified under six heads.

(1) The direct method of selected 'type' families, which is extremely dull.

(2) The historical method, which is wasteful of time as a basis for modern teaching.

(3) Philosophical method. This could be properly effected only with students already possessing considerable experience.

(4) Phylogenetic method. This is the easiest method to teach; but the dangers are that speculations would be taken for established fact.

(5) Practical. Here there are several different approaches; but in all it is essential that the student shall handle material himself and learn to work out characters, constancies and correlations from specimens and not from lecture notes. Advantages are that learning is easy, initiative is at a premium and the research habit is developed.

(6) Synthetic method. This is the method for the future whereby all the good points under the preceding five headings are combined and the bad ones are eliminated. How far is this synthesis possible?

There are clearly two types of botanist, taxonomist and non-taxonomist; but the latter should have a sufficiently wide knowledge of taxonomy to be able properly to appreciate its purpose, methods and problems. Taxonomy cannot be learnt by the 'type' method. Its very essence is the detection of correlations. Selection of material is essential ; but too early specialization must be avoided. Early on, the need for a universally recognized system should be simply explained and theories concerning it briefly 
outlined. Students should then be turned loose in the field with a flora to work out the plants of an area for themselves. Later there should be concentration on a few families limited to the local flora: not as 'types' but for the study of character evaluations, correlations, variation and reticulation. Then there should follow the study of a single genus in detail, perhaps extended to extra-British species.

Since the British flora is too limited to furnish a full appreciation of variation of structure and behaviour, serious study should eventually be made of at least one tropical family.

Detailed theories of classification should be deferred until the student has acquired sufficient facts to appreciate the linkage of practice and theory; but suggestiv $\theta$ generalizations should be introduced gradually as factual knowledge grows, and to this end modern methods and detail should replace historical subjects. An experimental garden is essential, since in it students can learn much of fundamental importance, such as distinctions between phenotype and genotype, character plasticity, genetic isolation, etc. The study there of species problems will lead to integration of orthodox taxonomy not only with morphology but also with all that is latest in plant physiology.

The number of posts for professional taxonomists is limited. Only those students who have a definite flair for it should be encouraged to take it up as a career. Only a few universities are at present equipped to give the necessary specialized training. Other university departments of botany should aim at giving their students a sound general training, as already outlined, and leave specialized training to a postgraduate apprenticeship period at some centre of taxonomic research.

MR. PETER BELL (UNIVERSITY COLLEGE, LONDON) regretted the omission from Dr. Ashby's paper of aspects of training bearing on the teaching of botany in schools, since most present-day students came up lamentably equipped for a modern course in botany. The analysis of subjects chosen for research by recent graduates was of no significance in the discussion, since such choice was dictated primarily by the availability of money for specific subjects.

He could not agree with Dr. Ashby that the specific requirements of government departments for special types of botanist should be allowed to influence the content of an honours degree course. He did, however, agree with his two principles of teaching, that is, doing a few things well and becoming familiar with the workings of powerful intellects. This first principle was frequently adopted in morphological teaching. The difficulty of dealing with the second would be to decide who were the great minds in the botanical world.

Turning to Dr. Ashby's concrete suggestions for reform, he held that students could not be divided readily into "naturalists" and "experimentalists". "There was a complete dovetailing of both these aspects over the whole field of botany. Up to graduation the botanist's training should therefore ibe general, and special accessory knowledge for experimental research, for example, statistical methods, physical chemistry, etc., should be picked up when the need arose in postgraduate years. A general view of the advances in the whole subject was essential for anyone attempting research in botany.

In the informal discussion which followed, most of the speakers agreed that Dr. Ashby's suggested reform required specialization at much too early a stage, before students could be reasonably expected to have decided precisely what aspect of botany they wished to follow.

DR. H. HAMSHAW THOMAS (CAMBRIDGE) said that botany courses could and should provide a real intellectual training for students, by no means all of whom were destined to become professional botanists. This should include the writing of clear and intelligent English and an appreciation of the meaning and implications of words. He hoped that Dr. Ashby's suggestion that we might profitably copy the excellent teaching methods of the classicists would be given careful attention.

PROF JOHN WALTON (UNIVERSITY OF GLASGOW) said that the training of research workers in a special line should be left to the Ph.D. period, when they should take courses in those allied subjects that they specially required, for example, biochemistry, statistics, genetics, etc.

DR. JOHN RAMSBOTTOM (FORMERLY BRITISH MUSEUM (NATURAL HISTORY)) pointed out that botanical courses were designed originally for teaching botany as a discipline, almost entirely to intending teachers, and were correspondingly stereotyped. This tradition persisted. Before steps were taken, however, to make it difficult to study botany as a whole, an effort should be made to produce a more balanced and realistic syllabus.

DR. J. L. CROSBY (UNIVERSITY OF DURHAM) said that the history of botany should be an important part of any university course in order to understand how ideas have developed and to obtain full benefit from the botanical classics.

DR. J. HESLOP HARRISON (UNIVERSITY COLLEGE, LONDON) found it difficult to accept Dr. Ashby's proposition that botanical science could be divided into experimental and non-experimental. If those botanists who are to tackle the unsolved classical problems are to be segregated early from the physiologist stream, then this is the way to ensure that those problems are never solved. Little can now be expected from purely observational methods, and the past forty years have shown us that progress with these problems can best be achieved by application of experimental téchniques by those trained in physiology. Specialization must therefore be deferred at least until the student has gained some appreciation of the science as a whole, which is usually not until he has graduated after a broad general honours course.

DR. P. F. WAREING (UNIVERSITY OF MANCHESTER) suggested that 'botanists' did not appreciate the real point at issue. The modern plant physiologist requires a knowledge of very advanced chemistry and this cannot be 'picked up' when needed after graduating. Dr. Ashby's scheme was to meet this difficulty, and so far no other practical alternative had been suggested.

The student point of view was put by MR. J. E. DALE (KING'S COLLEGE, LONDON), who said that the good student would plan his own course of study, irrespective of academic direction. $\mathrm{He}$ is the person who ultimately decides where and when specialization will start.

DR. W. MATHIAS (UNIVERSITY OF LIVERPOOL) was sympathetic with the view expressed by Dr. Hamshaw Thomas that a university training should be non-vocational, but how many presentday students are stimulated by considerations other than vocational ? 
Dr. Ashby replied to the points made during the discussion. He said that the chief objection raised against his suggestions was that they involved specialization at too early a stage in the botanical course. But the honours student is committed to early specialization in any event; and it was therefore necessary to weigh its drawbacks against the advantages of a thorough training. L. J. Audus

\section{Further Contributions}

Prof. L. J. Audus, Bedford College, University OF LONDON

The modern professional botanist, whatever his particular specializations, must possess a proper appreciation of modern concepts on form and function in the plant kingdom. For this he needs, in addition to his general botanical training, a thorough grounding in chemistry, physics and mathematics and a knowledge of certain aspects of these subjects as deep as that possessed by the relevant specialist. In addition, the experimental botanist entering Government or Colonial Service needs a knowledge of special techniques that can be neither quickly nor easily acquired. It is altogether too optimistic to suggest that all this can be squeezed into a three-year honours course, even with the modifications and omissions proposed by Dr. Ashby.

A fourth postgraduate year for specialized training is essential if we are to avoid turning out mere 'technicians' as a result of too early and too narrow a specialization. The courses in the three pre-graduate years need not differ in structure from those at present in operation except that physics and chemistry of an appropriate type and standard should be obligate subsidiary subjects. Specialization in botany should not be carried quite as far as it now is in some honours schools, but extra time should be devoted to particular associated techniques, for example, statistics, etc. In the postgraduate year the specialization could be as extreme as the particular types of training demand and could terminate in an M.Sc. by examination. The school teacher would, as now, follow the course up to the first-degree stage. and this would avoid the invidious distinctions, implicit in Dr. Ashby's suggestions, between professional botanists and school teachers, whose prestige has already fallen dangerously low. We must nurture our prospective teacher on the same inter-. esting diet as we nurture our prospective research workers or we destroy at the source the interest and enthusiasm of our future professional botanists.

Prof. T. A. Bennet-Clark, F.R.S., King's Collegh, UNIVERSITY OF LONDON

Ir was evidently suggested by many speakers that Dr. Ashby's proposed reforms required specialization at too early a stage, and the astounding view was even expressed that "physical chemistry, etc., could be picked up" after graduation. Incidentally, why not pick up extra morphology after, rather than before, graduation?

All this reads like the most unwelcome proposition that pure botany is more desirable academically than a broadly based scientific training with appropriate chemical, physical and biological disciplines. To regard this pure botany as less specialized than Dr. Ashby's experimental course is incomprehensible.

The narrow specialization of the botany of fifty to sixty years ago represents a very arbitrary segregation of a single compartment of natural knowledge largely determined by the direction of research in the eighteenth and early nineteenth centuries. It is no longer a very convenient subdivision, if students are to be forced by syllabuses or regulations to remain confined within it, when current research advance is in the so-called borderline sciences. My support for reform on lines like those suggested by Dr. Ashby is based on the belief that such reform could permit less specialization than frequently occurs now and that it should also blur the very arbitrary sharp boundaries between the sciences. Different universities would no doubt attempt different patterns of reform to permit easy integration of the basic sciences.

Prof. G. E. Briggs, F.R.S., University of CamBRIDGE

The system of training botanists which Dr. Ashby criticizes and that which would result if his amendments were adopted are different from that which has developed at Cambridge. As it has been intentionally adjusted from time to time as the subject has developed, it may be useful to others to describe its present state.

During his first two years a student must read at least two other sciences chosen from a wide range, including mathematics, the only restriction being that of the time-table. For example, he can combine chemistry, physics and mathematics with his botany or he may read zoology and geology. A common combination is botany and zoology with organic chemistry and biochemistry, the two latter together counting as one subject. In his third year, when he reads only botany, he is encouraged to attend lectures and practicals in all branches; but the examination allows for specialization.

The bias of the university staff is allowed to have an influence. No attempt is made to cover the whole field of botany, nor do we try to deal with all the sub-sections of a section such as plant physiology. By dealing with the parts of which he has special knowledge, the lecturer hopes to form habits in the student which will be generally useful to him at a later stage.

\section{Prof. A. R. Clapham, University of Sheffield}

Dr. Ashby is surely incorrect in saying that "by and large, the honours botany curricula contain as much comparative morphology, etc., as they did in 1910" : there are several university departments in which only one or two selected groups are treated in the old detail, the time so saved being devoted to modern branches of botany, experimental or nonexperimental. I agree with him that honours courses should not be lengthened; but I agree with Dr. Peter Bell and others that there should be no division of the undergraduate class into 'naturalists' and 'experimentalists'. Students cannot be clearly divided into such categories, and they should not be obliged to make the implied decision before they take their first degree. I have known many whose primary interests were taxonomic or ecological but who were either experimentalists by inclination or who at least recognized the desirability of a training in experimental attitudes and techniques. Such men ensure that no branch of botany remains non-experimental, and they contribute in a most valuable way to botanical progress.

It is, moreover, undesirable that there should be any lessening of the opportunities for contact between honours students of diverse interests, for this contact plays an important part in undergraduate training. The experience of many botanical departments is 
that it is not difficult, by the careful designing of courses and examinations, to continue to give a wide botanical training and yet to foster special interests to an adequate extent. If these courses remain at their present length there is time for narrower specialization in postgraduate courses of training in research.

Prof. Ronald Good, University College, Huld

Many will agree with Dr. Ashby's diagnosis that the problem now facing teachers of botany in universities is due partly to the growth in content of that subject and partly to a tendency for it to become increasingly vocational, though how far the former reflects the latter may be more debatable. It is often suggested that some reduction of the burden by a process of sub-division or dichotomy has become inevitable, and it is therefore important to remember that there is more than one way in which this might be achieved. That most commonly mentioned is by division on the basis of subject-matter, which may be called the 'physiology or morphology' point of view, but there is also the possibility of making the division more clearly one between the academic and the technical.

The real trouble is that at present the fiction that the whole subject of botany can still be taught in a. single manner for all purposes results in too frequent failure to do the thing which matters most, namely, to provide, in Dr. Hamshaw Thomas's phrase, "a real intellectual training for students". Might not the inevitable dichotomy be better made between students rather than between parts of their subject, so that the training of those with greater natural scientific aptitude might be different from, and perhaps more academic than, that given to those whose gifts lie more in the application of knowledge? If this is indeed the direction in which a solution of the problem is to be found, however, then one cannot but wonder how long a design of higher education which contains only one pattern of university institution and but a single system of degrees will continue to be entirely sufficient.

Prof. F. G. Gregory, F.R.S., Imperial CollegF of Sctence and Technology, London

In recent years botany has developed rapidly as an applied science: in $(a)$ pathology, $(b)$ plant breeding, (c) agronomy or crop physiology. Meanwhile botany remains as before a pure science embracing anatomy, morphology, systematy and physiology. The curriculum should be adjusted to both these needs. It will inevitably be influenced by the interests and capabilities of the teaching staff.

Dr. Ashby's suggestions for the reform of the curriculum seem acceptable and indeed are urgent. There are two types of botanical students, and after the preliminary post-intermediate first year both types should be catered for by a bifurcation in the direction Ashby has indicated.

Perhaps one should go even further in the interests of applied botany, and after the second post-intermediate year separate those who incline towards mycology and plant pathology from those whose interests are physiology and microbiology. In the third post-intermediate year the physiologists should spend a considerable part of their time in the study of advanced organic chemistry, enzymology, biochemistry and physical chemistry.

It may be necessary eventually to separate off physiology completely as an independent discipline.
Such a reform would entail a much closer liaison between the teaching departments in the physical and biological sciences and would necessitate an increase in the staffs of the physics, chemistry and biological departments.

Prof. F. M. Haines, Queen Mary College, London

It is agreed that the curriculum for different types of student should be even markedly different and that the different types of student can be recognized by their preferences and aptitudes at an early stage. At the same time, the first essential is to provide opportunity for studying the subject so far as possible as a coherent whole. In doing so, moreover, some preferences change and further aptitudes develop. The now patent dependence of, for examples, taxonomy on cytogenetics, of cytogenetics on biochemistry, of anatomical structure, life-histories and ecology on physiological principles and so forth, emphasizes the artificiality of segregating different aspects of the subject or divorcing any from the rest.

The principles of the different disciplines should be taught side by side for as long as the corpus of knowledge allows and segregated only to the minimum dictated by teaching convenience. The University of London regulations already allow a choice of ancillary subjects to be followed prior to the attainment of the standard of the General Degree, these being optional and suited to the student's aptitude and outlook; they also allow a considerable degree of specialization in the final pre-graduate year, in which the born taxonomist noed not be tortured by any further physiology, or physiologist by further morphology. Further specialization, or at an earlier stage, is not necessary at all events yet, and though deplorable enough on the grounds indicated above, would be even more so to those who still look to a university course for educational or cultural as well as vocational development.

Prof. T. M. Harris, F.R.S., University of Reading

Dr. Ashby deals mainly with the honours course with supporting subsidiary subjects; but my direct experience has been with the systems of Cambridge and Reading, where a student reads three equal subjects, takes a degree examination and then possibly a final year on botany alone. However, his remarks apply here also, and I am sure the course is apt to be overloaded.

It is difficult to lighten the B.Sc. General all round without skimping practical work and reading; it seems that some neglect is better. I think this can be left to the student by giving him more choice in examination so that he can safely drop certain fractions of the course. This spares him revision and reading; but I would make him do nearly all the class work so that he knows what he is doing.

The B.Sc. Special course at Reading is a graduate course for a very few selected students, and as they are allowed to do pretty well what they want, its faults are outside the scope of Dr. Ashby's remarks.

Finally, may I plead for more liberty of choice for the student? I believe that in the years I have seen, planning has narrowed the field of liberty even in university education, and almost entirely to the detriment of the best students.

Prof. C. T. Ingold, Birkbeck College, University OF LONDON

Universities are not concerned with turning out graduates in botany tailor-made for applied research. Those employing botanists should be prepared to 
select graduates of the right calibre. Their training in the advanced techniques necessary for the particular job should come later.

Some measure of specialization for the student in his final year (not earlier) is desirable and necessary because of the huge body of botanical knowledge. In most universities this is already normal practice. Further, all students should have the intellectual satisfaction of pursuing a small problem in some branch of botany at leisure. This is achieved in many departments by honours students undertaking a 'special study' or 'minor thesis' in the final year or in the preceding vacation.

The division of students into experimentalists and non-experimentalists is highly undesirable. The morphologist, taxonomist, mycologist, geneticist and ecologist, no less than the plant physiologist, must now make the experimental approach to problems. The so-called "classical problems of morphology" consisting in the main of theories, which cannot be tested by experiment, concerning the phylogeny of organs and of larger systematic groups, no longer command the attention of many academic botanists.

During their course honours students should have an opportunity of seeing the work of research stations and of the national museums. Students thinking of government employment as botanists should, where possible, undertake vacation work at some research institute or at a national taxonomic centre. This is becoming increasingly common.

Dr. W. O. JAMES, F.R.S., UNIVERSITY OF OXFORD

It is difficult to comment constructively on Dr. Ashby's suggestions on account of their point of departure. Honours courses in botany should not be based on his explicit assumptions that the 'bias' of the available staff may be disregarded, and that the courses are a training only for professional botanists. Botany has a much wider value in higher education than self-propagation.

We should not, I think, allow ourselves to be browbeaten by a term, even of so impeccable an appearance as over-specialization. Botany students are of many kinds, not of two only, and a degree of specialization that might poison one may be meat to another. Nothing has impressed me more than the transformation that comes over many students when they pass from the classwork stage to the specialist. The real objection to Dr. Ashby's dichotomy is that it is likely to prove impracticable and seems undesirable. Observation and experiment are still' the 'Siamese twins' of botany, and the attempt to dissect them would prove dangerous to the more experimental side and perhaps fatal to the other; much of modern taxonomy and morphology is labelled experimental. Neither does it appear probable that the training proposed for experimentalists would enable more than a few to read many modern papers on photosynthesis. Where two sciences converge, the future lies with those who are willing to co-operate on a basis of knowledge of their own discipline with respect and sympathy for the other. The biologist for the team will be more useful if he is widely trained in biology than if he is given a second-rate knowledge of chemistry and physics.

In a three-year honours course, the first year should be non-specialized in the sense that it ranges over the whole subject. Since students hate the apparent repetitions of a concentric system, it should not be a prospectus to be filled out later, but a definitive treatment of topics chosen for their relative ease of absorption. There should also be courses in methodology with round-the-bench discussion. Collateral reading should be judiciously selected, but could not, I am afraid, lean very heavily on the original publications of the great botanists. Unfortunately, the great botanists have not been great writers, and botany has yet to produce its D'Arcy Thompson.

The two subsequent years should continue with the same collateral plan, the major divisions of botany being built up side-by-side. By the end of the first year most students have discovered their preferences and should be allowed to specialize by a moderate discard of topies. In smaller departments this will inevitably be done for them by the 'bias' of the available staff. On no account should 'dead' lecturing on mugged-up material be tolerated in honours courses. If there is to be a Part I examination, it should come at the end of the second year. This plan I believe to be both more realist and more desirable than a naturalist-from-experimentalist split of the subject.

Prof. F. W. Jane, Royax Holloway College, UNIVERSITY OF LONDON

That the honours student is committed to early specialization is incontestable; how early, it is difficult to decide. Modern botany shows a trend toward convergence of its several branches, researches in cytotaxonomy, experimental morphology or biochemical mutants, for example, indicating an increasing synthesis of the various aspects of the subject. Precocious specialization would handicap the student in appreciating this modern approach, and he would be less likely to contribute to its progress later. Moreover, in a science which is becoming increasingly experimental, any attempt to segregate students into experimentalists and nonexperimentalists seems neither practicable nor desirable. The best initial equipment for any botanist is surely some understanding of living plants, a recognition that they have form as well as function, an environment as well as a history. Early specialization would not foster this understanding.

If the supply of botanists greatly exceeds the demand, many graduates, despite specialization, are likely to become school teachers, concerned with teaching elementary botany, training in which has now been relegated from the universities to the schools. Here, surely, specialization would even prove a liability.

While the vocational aspect of a university course inevitably bulks large, it should not obscure the need for a purely intellectual training or discipline. I like the individualistic outlook of $\mathrm{Mr}$. J. E. Dale: it implies, and I believe truly, that the worth-while student will follow his own bent and achieve success, in spite of, rather than because of, what his tutors may do to guide him.

Prof. Irene Manton, University of Leeds

IN my view the only effective way of increasing the quality of the scientific training of botanists without imposing too early specialization, which would defeat its own ends by unbalancing the teaching in schools, is to make available such resources as are most strongly represented in our best departments to a greater range of students than is now the case. This could, I think, be done most effectively by offering a limited number of postgraduate courses of full-time study of perhaps a year's 
duration, leading to a special qualification such as the M.Sc. by examination, in certain special fields with exacting technical requirements, for example, advanced plant physiology, cytogenetics or biophysics, taxonomy and/or ecology, to name a few at random, on the lines already initiated by the University of Nottingham in its postgraduate course in mycology, and by the University of Sheffield in its similar treatment of biochemistry. Such courses would precede and be the basis for the narrower and in many ways very different training in research on a specific problem which our present Ph.D. students receive.

Such courses would impose a heavy strain on departments giving them and might perhaps in certain cases be held in alternate years or be shared in some way between several strong departments. Use could also appropriately be made of departments in the Commonwealth since, for example, the University of Malaya might be better placed to offer an intensive postgraduate training in angiosperm taxonomy than a British department. Co-operation and some co-ordination between universities would be essential to prevent overlapping. Some adjustment of postgraduate financing of students would be needed, and in some universities it may be necessary to overcome prejudice against the use of higher degrees for such purposes. If these difficulties could be overcome, the technical qualifications of our best students for careers other than school teaching would be greatly enhanced without disturbance to existing undergraduate curricula.

Prof. J.R. Matthews and P. J. Faulks, University of AberdeEn

The steadily increasing content of botanical science suggests the need for a revision of the teaching curriculum, and Dr. Ashby's proposed modifications are a possible solution of a real difficulty. While too early specialization in undergraduate training is to be deprecated, provision should be made in the final year (fourth year in Aberdeen) for a student to receive specific training in a selected branch of the subject. This depends partly upon the student's real interests and aptitudes (which the good student seeking to become a professional botanist will have discovered for himself) and partly upon his proficiency in ancillary subjects.

A fair measure of specialization in the final year will at least enable the student to begin the process of fitting himself for his future career ; for no undergraduate course of normal duration can expect to complete the task. Special training, however, is valuable only in so far as it is based upon a sound foundation of botanical knowledge which must be laid in the first three years. All students should receive a general training in morphology and physiology, and time can be saved for certain 'modern essentials' if classical theories are not elaborated in the early years. They should also derive from abundant practical illustration, rather than from formal teaching a knowledge of taxonomy, while a 'modern essential' for all students is an introduction to the design and analysis of experiments. The vocational aspect frequently influences the student's final choice of 'specialism', and it should be recognized that not every school of botany can specialize in every branch of the subject.

Prof. R. C. Mclean, University College, Cardiff

Dr. Ashby's paper gives expression to a concern that has been steadily growing in the minds of teachers in recent years : how to make terms with the future. The problem can only get worse, and a solution must be found. To continue giving all students a sketch of everything, old and new, is entertaining and may broaden their minds, but it is not the way to train professional botanists. Subsequent speakers did not all appreciate Dr. Ashby's limitation of his argument to that aspect.

There are two ways to meet the situation. One is that of the mathematicians, to confine undergraduate courses to the classical aspects of the subject and leave exploration of the frontiers until the postgraduate period. Unfortunately, our frontiers are too close to us to be ignored, and the alternative obliges us to contemplate some such dichotomies of study as Dr. Ashby suggests. A canalization of interests will be forced upon the botanist as soon as he begins professional life: why not recognize this situation and prepare him for it by better (which means wider) training along the lines of his aptitudes. This is where the bias of staffs comes in--not always illegitimately, I beg to think. I am not impressed by the argument that one cannot distinguish between observational and experimental aptitudes during a student's training. Nearly forty years of university teaching has led me to the contrary opinion.

A broad preliminary course is certainly essential; but those who shake their educational heads over subsequent specialization are ignoring the immense capacity for self-teaching possessed by the good mind. It is quite possible for a physiologist to develop an intimate knowledge of the Bryophyta, for example, on no more than an elementary basis, and we could all multiply instances of men who have successfully combined specialization with broad and varied interests of their own choosing. To broaden his outlook is a man's own task; what he is taught is, happily, not the decisive factor.

Prof. P. W. Richards, University College of North Wales, Bangor

I agree with so much of what Dr. Ashby has said that I hesitate to range myself among his critics. The 'dilemma of the curriculum' faces every teacher of a rapidly growing science such as botany ; but I think Dr. Ashby's solution is based on a dangerous over-simplification of the real situation. As Mr. Bell said, students do not fall into two classes only-the 'experimentalists' interested in applying physics and chemistry to plants, and the 'naturalists'. Both the needs and the aptitudes of students are more varied than that, and if we forget this and plan the botanical curriculum as Dr. Ashby proposes, we shall provide badly for many who do not belong exclusively to either class, such as geneticists, ecologists and plant pathologists. The ecologist, for example, needs training in plant physiology (except perhaps for its more 'biochemical' aspects) as much as in systematics; but how would he fit into Dr. Ashby's 'dichotomous' curriculum ? My own solution would be to divide the subject not into two, but into seven or eight, branches and allow the student to specialize in a reasonable number of these.

Apart from objections in principle, I foresee great difficulties in applying Dr. Ashby's suggestion, except in a very large and well-staffed department. In one such as my own without a large staff, and in which future professional botanists form only a small minority of the students, these difficulties would probably be insuperable. 


\section{Prof. M. Skene, University of Bristol}

Dr. Ashby's acute analysis is very welcome. The problems arising from the increasing amount and range of knowledge are felt by all botanists. There may be less agreement on the solution suggested; indeed, it may be that no uniform plan is desirable.

In undergraduate work we should educate botanists and not train them for particular botanical jobs. All undergraduates should have the same general education. The morphologically minded should gain good experience in experimental work; the physiologist should know how to handle a variety of plants. Natural bias in ability and interest can be allowed for in the setting of the examination papers.

Botany is the meeting-ground of many sciences, and the advantage of this in a liberal education should not be lost: nor is the dichotomy so sharp as Dr. Ashby suggests. The plant pathologist is a good example of a specialist who must be competent in both fields.

The exhaustive study of a few types is valuable in giving depth ; but the method should be judiciously tempered by opportunities for getting to know a large variety of material. Diversity of creatures is the essence of living Nature, and, to many, the spice of biological study.

The employers of botanists should not expect the new graduate to be ready trained for a special job. The necessity for this training remains. It would best be met by postgraduate diploma courses of about one year's duration. Such courses might well be shared out between the universities. For very many graduates they would be more useful than the years spent in research leading to a higher degree.

Prof. M. Thomas, F.R.S., King's College, NewCASTLE UPON TYNE

The few words available may be used most economically to state present practice at King's College, Newcastle upon Tyne, in framing "honours courses in botany considered solely as a training for professional botanists (not including school teachers)", to which Dr. E. Ashby limited the scope of his address. We have been experimenting for a number of years, and realize that there is much scope for further experiment.

At present we require all honours students to study all post-intermediate courses given over two complete sessions in the Department of Botany. They all thus cover the ground for the final pass (general) examination. In their third and final year each honours student is informed that about two-thirds of the course is the maximum he can be expected to cover. Experience has shown that the combination of interests varies with the student. The special study of taxonomy has been combined with that of molecular events.

Our view is that the problem of each honours student requires individual consideration, which is extended to the selection of auxiliary subjects. We consider that some knowledge of chemistry is desirable for all ; but chemistry is not a compulsory subject. Intending physiologists often extend their chemical studies over two years. As regards our other special izations, zoology has been the most favoured subject for two years of study by intending eytogeneticists and field ecologists. Bacteriology has been studied with much profit by students now carrying out graduate research in mycology. Students having the necessary mathematical ability have been encouraged to study physics above an elementary level.
More than ten years ago two students of special honours quality graduated in what might be regarded as a joint honours school in physics and botany, and another student in chemistry and botany. Unfortunately these combinations of subjects have not been taken in recent years. A case could be made for such schools rather than special honours in botany for certain picked students competent to study physical as well as biological science to a high level.

\section{Prof. T. G. Tutin, University College, Leicester}

I cannot altogether agree with Dr. Ashby that the solution of our difficulties lies in earlier specialization. Taxonomists and morphologists are at last applying experimental methods to their studies, and some knowledge of mathematics, physics, chemistry and plant physiology is essential if they are to make real progress.

It is of particular importance in this connexion that the chemistry which botanists learn should include more physical and organic chemistry and less about the lead-chamber process.

For a sound training in botany a four-year course seems desirable to-day, if financial considerations will permit it ; the first two years can then be spent on a general course in three subjects, chosen in accordance with the special interests of the student, the next year on a wide botanical course and the final year in specializing in a particular part of the subject. Recent experience here has clearly demonstrated the great value to the student of being able to spend four years over the degree course. The acceptance by many universities of the General Certificate of Education at Advanced Level as a substitute for Intermediate greatly increases the desirability of a four-year degree course, since students often arrive at the university with little real foundation for their subsequent studies.

A less satisfactory, though perhaps more practicable, alternative might be to retain the three-year course with a less detailed treatment of the groups of cryptogams in the first two years and then to allow considerable specialization in the final year.

Finally, would it be unkind to suggest that the pure "naturalists" with no aptitude for experiment or interest in physical sciences should be encouraged to take an arts degree and pursue botany as a hobby?

Prof. D. H. Valentine, Durham Colleges in the UNIVERSITY OF DURHAM

I am in general agreement with Dr. Ashby's proposals ; but I would suggest some modifications. First, I do not think an honours student should choose his subject until, at earliest, the end of his first year at the university; it is not uncommon for a student to change his mind about his subject, and I think it is well that he should be able to do so. Secondly, I think that it is most undesirable to widen the division between botany and zoology, as Dr. Ashby seems to suggest. On the contrary, I think the subjects should, so far as possible, be brought closer together. Thus, I should like to make it possible for students who have had a good introductory training in both disciplines to specialize in their final year in, say, evolutionary studies, or animal and plant ecology, or cell physiology; the courses would be provided jointly by both botany and zoology departments, with assistance from other departments where it was required. 
Prof. W. T. Wildiams, University of SouthampTON

I strongly support Dr. Heslop Harrison. There is room for a continuous spectrum of botanists, ranging from the pure morphologist to the biochemist, and it is the traditional task of any one of these to bring his chosen problem one stage nearer to the realm of the chemist. The rigid segregation of students into two groups, whatever its organizational advantages, might easily result in morphologists who are not interested in the physiological problems underlying their study, and in physiologists who are largely unaware of the vast fields of experimental morphology awaiting investigation. If a student genuinely wishes to specialize early, encourage him; but let us at all costs attempt to retain the possibility of training good general botanists, however difficult this may be.

\section{OBJECTIVITY OF COLOUR PREFERENCES}

\section{BY DR. G. W. GRANGER}

Psychology Dept., Institute of Psychiatry, Maudsley Hospital, London, S.E.5

$I^{\mathrm{T}}$

$\Gamma$ has long been supposed that colour preferences are entirely a matter of personal taste, depending on individual associations and other subjective factors, and the results of numerous experimental studies have seemed to support this view. Thus, Chandler in his survey of research on colour preferences remarks that the results of these experiments are "chaotic"; the most careful and thorough work of such acknowledged authorities as von Allesch" serves only to emphasize the fact that observers disagree sharply as to the relative preferential value of single colours and colour combinations.

This apparent lack of agreement has led those psychophysicists and sensory psychologists who have explored in great detail the 'objective' stimulus dimensions of colour to dismiss the æsthetic, affective or preferential values of colours as purely subjective and outside the scope of present-day scientific analysis. For quite different reasons, æstheticians and psychologists of Gestalt persuasion have declared the whole realm of colour æesthetics to be beyond analysis by the ordinary atomistic and dimensional methods of science. Such writers argue that this field is characterized by "emergent properties" which cannot be accounted for in terms of parts and relations between parts as Spearman $^{3}$ and other elementalists have claimed; at every turn the investigator is confronted by Gestalt or whole qualities that defy analysis.

Recent experiments by the author suggest that neither of these two extreme views, the subjective nor the Gestalt, is justified; indeed, the evidence seems overwhelmingly in favour of objective and fairly atomistic hypotheses. As detailed accounts of the individual experiments on which this evidence is based will be published elsewhere, only a general summary will be presented in this paper.

In the first experiment, sixty sets of standard Munsell colours were selected to represent the entire colour solid along its three principal dimensions hue, lightness and saturation. Within each set the colours were ranged in order of preference by fifty

* Substance of a lecture to the Colour Group of the Physical Society delivered on February 13 . subjects (twenty-five men and twenty-five women) of normal colour vision, as tested by the Ishihara ${ }^{4}$, Rabkin $^{5}$, and Farnsworth-Munsell ${ }^{6}$ tests. Illumination at $6,500^{\circ} \mathrm{K}$. was provided by a specially calibrated tungsten lamp in conjunction with a Macbeth daylight filter, and the colours were viewed against a neutral grey background of Munsell value 5. When subjects' rankings were summed for each set and the amount of agreement calculated in terms of Kendall's ${ }^{7}$ coefficient of concordance $(W)$, it was found that the resulting coefficients reached significance at the $P<0.01$ level, indicating quite clearly that the subjects were not independent in their preferences; on the contrary, they showed a remarkable degree of concordance, the average value of $W$ being about $0 \cdot 3$. Further, it appeared that the general order of preference for any one attribute of colour (which remained invariant at different levels of the colour solid) was dependent on stimulus properties in the following way: hues of shorter wave-length tended to be preferred to those of longer wave-length, the more saturated colours were preferred to the less saturated, and colours which contrasted least in lightness with the background were ranked higher than colours showing maximum contrast. Conclusions were necessarily tentative, owing to the small number of items involved in the general order of preference. Contrary to some earlier claims, no marked differences were found between the preferences of men and women.

A second experiment was undertaken in which preference judgments were obtained from twenty subjects for four sets of colour combinations. Three of the sets represented variation along each of the principal dimensions of colour, while the fourth contained fully saturated hues which had been used in a previous experiment by Clarkson, Davies and Vickerstaff $^{8}$. Preference judgments for the hue, lightness and saturation tests were obtained against a background of neutral grey, while preferences for the combinations of fully saturated hues were obtained against a black background to facilitate comparison with the previous research in which this type of ground had been used. Data for all four tests were collected, as in the first experiment on single colours, under an approximation to C.I.E. ${ }^{\circ}$ illuminant $C$. When subjects' preferences were analysed, it was found once again that a large measure of general agreement existed for all four types of colour combination used in the experiment, and, as before, the general order of preference seemed to be dependent on objective stimulus properties: thus, preference tended to increase with increasing hue distance between the component colours making up the combinations, to decrease with increasing lightness, and to decrease with increasing saturation. This dependence was most striking in the case of hue combinations, where there was an almost perfect positive correlation between preference judgments and the size of hue interval between the components. Particularly encouraging was the independent confirmation of results obtained earlier by Clarkson, Davies and Vickerstaff. From data kindly supplied by Dr. T. Vickerstaff, it was possible to calculate correlations between preference judgments and hue interval, and when this was done, the resulting coefficients exceeded 0.95 -somewhat larger than those I have obtained for combinations of fully saturated hues.

Finding that preferences for combinations of hues could be accounted for almost entirely in terms of 